\title{
Thymosin $\beta 4$ promotes hepatoblastoma metastasis via the induction of epithelial-mesenchymal transition
}

\author{
XIAOJUN FU ${ }^{1}$, PEIYUAN CUI ${ }^{2}$, FANGFANG CHEN ${ }^{1}$, JIANZHONG XU ${ }^{1}$, \\ LI GONG $^{1}$, LEI JIANG ${ }^{1}$, DAKUN ZHANG ${ }^{1}$ and YONGTAO XIAO ${ }^{3}$ \\ Departments of ${ }^{1}$ Pediatric Surgery and ${ }^{2}$ Hepatobiliary Surgery, The First Affiliated Hospital of Bengbu Medical College, \\ Bengbu, Anhui 233004; ${ }^{3}$ Shanghai Institute of Pediatric Research, Shanghai 200092, P.R. China
}

Received May 16, 2014; Accepted January 27, 2015

DOI: $10.3892 / \mathrm{mmr} .2015 .3359$

\begin{abstract}
Hepatoblastoma (HB) is the most common malignant hepatic tumor in children and complete surgical resection offers the highest possibility for cure in this disease. Tumor metastasis is the principle obstacle to the development of efficient treatments for patients with HB. The present study aimed to measure the expression levels of thymosin $\beta 4$ (T $\beta 4)$ in liver samples from patients with $\mathrm{HB}$ and to investigate the involvement of T $\beta 4$ in HB metastasis. The expression of T $\beta 4$ was significantly higher in liver samples from patients with metastatic HB and in the HepG2 metastatic HB cell line, compared with that in adjacent healthy liver samples and in the L02 healthy hepatic cell line. By contrast, the expression levels of epithelial-cadherin (E-cadherin) and cytosolic accumulation of $\beta$-catenin, the two most prominent markers involved in epithelial-mesenchymal transition (EMT), were reduced in liver specimens from patients with metastatic $\mathrm{HB}$ compared with that of healthy adjacent control tissue. HepG2 cells were transfected with small interfering-RNA in order to downregulate $\mathrm{T} \beta 4$ gene expression. This resulted in a reduced cell migratory capacity compared with control cells. T $\beta 4$ gene expression knockdown significantly inhibited transforming growth factor $\beta 1$-mediated-EMT in vitro by upregulating the expression of E-cadherin. The results of the present study suggested that $\mathrm{T} \beta 4$ may promote $\mathrm{HB}$ metastasis via the induction of EMT, and that T $\beta 4$ may therefore be a target for the development of novel treatments for patients with HB.
\end{abstract}

\section{Introduction}

Hepatoblastoma (HB) is a type of liver cancer, which is common in children (1). The primary challenges for the improve-

Correspondence to: Dr Yongtao Xiao, Shanghai Institute of Pediatric Research, 1665 Jiangpu Road, Shanghai 200092, P.R. China

E-mail: ytxiaocell@163.com

Key words: hepatoblastoma, thymosin $\beta 4$, metastasis, epithelial-mesenchymal transition, children ment of treatment efficacy include HB metastasis and drug resistance $(2,3)$. Understanding the molecular mechanisms underlying HB metastasis may be useful for the development of novel therapeutic gene targets and the identification of diagnostic biomarkers for HB. Epithelial-mesenchymal transition (EMT) is associated with the progression of a number of epithelial tumors (4-6). EMT consists of a coordinated series of stages, where epithelial cells lose their cell polarity and their cell-cell adhesion, and develop into mesenchymal cells, which results in tumor invasion and metastasis. The process of EMT is essential for HB metastasis and invasion to occur $(7,8)$.

Thymosin $\beta 4$ (T $\beta 4)$, a small peptide originally isolated from calf thymus, is found in human tissues and blood platelets. $\mathrm{T} \beta 4$ predominantly functions as a $\mathrm{G}$-actin sequestering factor, modulating the dynamic changes of the actin cytoskeleton. In addition, T $\beta 4$ may be involved in a number of physiological and pathological processes, including the migration of fibroblasts $(9,10)$, endothelial cells and keratinocytes $(11,12)$, and wound healing $(13,14)$. In addition, the prospect of targeting $\mathrm{T} \beta 4$ in cancer therapy has recently been proposed. A previous study suggested that $\mathrm{T} \beta 4$ was overexpressed in osteosarcoma, colorectal carcinoma and esophageal cancer cells (15). Wang et al (16) demonstrated that $\mathrm{T} \beta 4$ overexpression suppressed epithelial-cadherin (E-cadherin) expression and led to the increased motility of SW480 human colon carcinoma cells. The present study therefore investigated the involvement of $\mathrm{T} \beta 4$ in $\mathrm{HB}$ metastasis.

\section{Materials and methods}

Materials and specimen preparation. Fetal bovine serum (FBS) was purchased from Gibco Life Technologies (Carlsbad, CA, USA). T $\beta 4$ was obtained from Prospec (Rehovot, Israel). Rabbit monoclonal anti-E-cadherin (cat. no 3195), rabbit monocloncal anti-neural-cadherin (anti-N-cadherin; cat. no 13116), rabbit monocloncal anti- $\beta$-catenin (cat. no. 9582) and rabbit monocloncal anti-glyceraldehyde 3-phosphate dehydrogenase (anti-GAPDH; cat. no. 9582) antibodies were obtained from Cell Signaling Technology Inc. (Danvers, MA, USA). Rabbit polycloncal anti-T $\beta 4$ antibody (sc-67114, for western blot analysis) was obtained from Santa Cruz Biotechnology, Inc. (Dallas, TX, USA). Rabbit polyclonal anti-T $\beta 4$ antibody (ab14335, for immunohistochemical and immunofluorescence analysis) 
was purchased from Abcam (Hong Kong, China). Mouse monoclonal anti- $\alpha$-smooth muscle actin (anti- $\alpha$-SMA; A5228) was obtained from Sigma-Aldrich (St. Louis, MO, USA). Lipfectamin RNAiMAX was purchased from Invitrogen Life Technologies (Carlsbad, CA, USA). Liver samples from HB and adjacent healthy tissue were obtained from 19 patients with HB at Xinhua Hospital and First Affiliated Hospital of Bengbu Medical College (Anhui, China). This study was performed according to a protocol approved by the faculty of the Medicine Ethics Committee of the First Affiliated Hospital of Bengbu Medical College. Written informed consent (BYKFD-2009-0914) was obtained from the patients' guardians prior to specimen collection.

Immunohistochemistry and immunofluorescence analysis. Immunohistochemistry was performed using a diaminobenzidine (DAB; Dako, Glostrup, Denmark) chromogen method as described previously (17). Specimens were initially incubated using xylol. Endogenous peroxidases were then removed by incubating the samples with $0.3 \%$ hydrogen peroxide. The primary antibodies (anti-E-cadherin, 1:400; anti-T $\beta 4,1: 1,000$; and anti- $\beta$-catenin, 1:100) were incubated overnight in a chamber with water bottom at $4^{\circ} \mathrm{C}$. The slides were washed in phosphate-buffered saline (PBS) and incubated with the horseradish peroxidase (HRP)-conjugated goat anti-rabbit immunoglobulin (Ig)G secondary antibody (1:200; \#7074; Cell Signaling Technology, Inc.). Antibody binding was visualized using a liquid DAB Substrate Chromogen System (Dako). In order to conduct an immunofluorescence assay, the cells were fixed with $4 \%$ paraformaldehyde. Subsequently, the cells were incubated with the anti-T $\beta 4$ antibody (1:200) and blocked using 3\% bovine serum albumin (MP Biomedicals, Auckland, New Zealand). Following three wash stages with PBS, the secondary antibody, conjugated to fluorescein isothiocyanate (1:200; \#111-095-045; goat anti-rabbit; Jackson ImmunoResearch, Inc., West Grove, PA, USA), was applied to the cells. The nuclei were counter-stained using 4',6-diamidino-2-phenylindole (DAPI; Dojindo, Kuma-moto, Japan). The results were visualized using a fluorescence microscope (Eclipse; Nikon, Tokyo, Japan). The nuclei staining and $\mathrm{T} \beta 4$ staining were then merged (magnification, $\mathrm{x} 40$ ).

Cell culture. The L02 human healthy liver and HepG2 hepatoblastoma cell lines were cultured in Dulbecco's modified Eagle's medium (DMEM; Gibco Life Technologies), supplemented with $10 \%$ fetal bovine serum (FBS; Gibco Life Technologies) at $37^{\circ} \mathrm{C}$ in a humidified atmosphere of $5 \% \mathrm{CO}_{2} . \mathrm{T} \beta 4$-small interfering RNA (T $\beta 4$-siRNA) duplexes were synthesized by Genepharma Co., Ltd. (Shanghai, China). The siRNA sequences were 5'-CUUCCAAAGAAACGAUUGATT-3' 5 ' - U C G A UA A G U C G A A A C UGA A T T-3' and 5'-GAGGUUGGAUCAAGUUUAATT-3'. T $\beta 4$-siRNA transfection was conducted using Lipfectamin RNAiMAX (cat. no. 13778; Life Technologies, Carlsbad, CA, USA) according to the manufacturer's instructions.

TGF- $\beta 1$ EMT in vitro. HepG2 cells were stimulated for $72 \mathrm{~h}$ in a conditioned medium containing TGF- $\beta 1$ (10 ng/ml), supplemented with $0.5 \%$ FBS. Total protein was harvested in order to conduct western blot analysis.
Western blotting. Protein concentrations of cell lysates were determined using a bicinchoninic acid protein assay kit (Pierce, Biotechnology, Inc., Rockford, IL, USA). Protein was separated using electrophoresis on a Novex ${ }^{\circledR} 10 \%$ Tris-glycine gel (Life Technologies) and transferred onto a nitrocellulose membrane (Life Technologies). The membranes were incubated with the following primary antibodies overnight at $4^{\circ} \mathrm{C}$ : Anti-E-cadherin $(1: 1,000)$, anti-N-cadherin $(1: 1,000)$, anti- $\alpha$-SMA (1:200), anti- $\beta$-catenin $(1: 1,000)$, anti-T $\beta 4$ (1:200) and anti-GAPDH $(1: 1,000)$. The membranes were then incubated with a HRP-conjugated anti-rabbit (1:2,000; cat. no. 7074) and anti-mouse (1:2,000; cat. no. 7076) IgG secondary antibody (Cell Signaling Technology, Inc.) after washing with PBS three times. The antibodies were detected using an enhanced chemiluminescence detection kit (Thermo Fisher Scientific, Waltham, MA, USA) and the Molecular Imager ${ }^{\circledR}$ ChemiDoc $^{\mathrm{TM}}$ XRS+ System (Bio-Rad Laboratories, Hercules, CA, USA).

Wound healing. Confluent cells in 6-well plates were scratched using 100- $\mu$ l pipette tips. The cells were then incubated at $37^{\circ} \mathrm{C}$ to allow cell migration into the wound. Following fixation, the number of cells that had migrated into the wound were counted using a microscope (Eclipse Ti; Nikon, Tokyo, Japan). Migration ratio (\%) was calculated as the wound width at $24 \mathrm{~h}$ /wound width at $0 \mathrm{~h}$.

Transwell migration assay. Migration of HepG2 cells was determined using 24-well Transwell chambers (Corning Life Sciences, Tewksbury, MA, USA), according to the manufacturer's instructions. DMEM $(500 \mu \mathrm{l})$ was added to the lower chambers of the 24-well plate, containing $10 \%$ FBS. Cells (1x10 $/$ well) were mixed with $100 \mu 1$ of DMEM without FBS, and the mixture was added to the upper chambers of the 24-well plate. Transwell chambers were incubated at $37^{\circ} \mathrm{C}$ in a $5 \% \mathrm{CO}_{2}$ humidified atmosphere for $24 \mathrm{~h}$. Cells that had migrated to the lower surface of the polycarbonate membranes (12-mm pore size) were fixed, stained with crystal violet (Amresco, Solon, $\mathrm{OH}$, USA) and quantified by counting five fields of view using a microscope (Eclipse Ti; Nikon; magnification, x40).

Statistical analysis. All data are expressed as the mean \pm standard deviation. Statistical significance for comparisons made between two groups was determined using Student's t-test analysis in SPSS version 13 (SPSS Inc., Chicago, IL, USA).

\section{Results}

T $\beta 4$ expression is associated with HB metastasis. The clinicopathological characteristics for the 19 patients with HB used in the present study are provided in Tables I and II. The expression of T $\beta 4$ protein in $\mathrm{HB}$ tumor tissue samples and adjacent healthy control tissues was analyzed. T $\beta 4$ expression was higher in $\mathrm{HB}$ samples compared with the adjacent healthy samples (Fig. 1). No significant associations were observed between $\mathrm{T} \beta 4$ expression levels and the gender, age or tumor subtype of patients with HB (Table I). T $\beta 4$ expression was significantly higher in metastatic HB samples compared with the that of the non-metastatic HB samples ( $91 \%$ vs. $25 \%$; $\mathrm{P}<0.01$; Table 1 ). Expression of $\mathrm{T} \beta 4$ in metastatic $\mathrm{HB}$ specimens was found to be increased, while E-cadherin expression as well as the 
Table I. Characteristics of patients with hepatoblastoma.

\begin{tabular}{|c|c|c|c|c|}
\hline Clinical parameters & $\mathrm{N}$ & $\mathrm{T} \beta 4 \mathrm{PR}(\%)$ & $\chi^{2}$ & P-value \\
\hline \multicolumn{5}{|l|}{ Gender } \\
\hline M & 14 & $9(64)$ & 0.13 & $>0.05$ \\
\hline $\mathrm{F}$ & 5 & $3(60)$ & & \\
\hline \multicolumn{5}{|l|}{ Age } \\
\hline$<3$ years & 13 & $8(61)$ & 0.00 & $>0.05$ \\
\hline$\geq 3$ years & 6 & $4(67)$ & & \\
\hline \multicolumn{5}{|l|}{ Tumor subtype } \\
\hline Fetal & 9 & $6(67)$ & & \\
\hline Embryonal & 5 & $3(60)$ & 0.23 & $>0.05$ \\
\hline Undifferentiated & 2 & $2(67)$ & & \\
\hline Epithelial/mesenchymal & 3 & $1(50)$ & & \\
\hline \multicolumn{5}{|l|}{ Lymph node metastasis } \\
\hline Yes & 11 & $10(91)$ & 8.65 & $<0.01$ \\
\hline No & 8 & $2(25)$ & & \\
\hline
\end{tabular}

$\mathrm{M}$, male; F, female; $\mathrm{N}$, number; $\mathrm{T} \beta 4 \mathrm{PR}$, thymosin $\beta 4$ positive rate.

Table II. Clinicopathological features and results of T $\beta 4$, E-cadherin and $\beta$-catenin immunostaining in hepatoblastoma samples.

\begin{tabular}{|c|c|c|c|c|c|c|}
\hline Gender & Age & Tumor subtype & LNM (Y/N) & $\mathrm{T} \beta 4$ & $\mathrm{EC}$ & $C \beta-c$ \\
\hline M & $8 \mathrm{Ye}$ & Fetal & $\mathrm{N}$ & $+/-$ & ++ & - \\
\hline \multicolumn{7}{|l|}{ M } \\
\hline M & $7 \mathrm{Ye}$ & Fetal & $\mathrm{N}$ & $+/-$ & - & - \\
\hline M & & & $\mathrm{N}$ & & & \\
\hline M & $5 \mathrm{M}$ & Fetal & $\mathrm{N}$ & $+/-$ & $+/-$ & - \\
\hline M & $4 \mathrm{Ye}$ & Embryonal & $\mathrm{N}$ & $+/-$ & ++ & - \\
\hline M & $13 \mathrm{M}$ & Embryonal & $\mathrm{N}$ & $+/-$ & $+/-$ & $+/-$ \\
\hline M & $15 \mathrm{M}$ & Undifferentiated & $\mathrm{N}$ & $+/-$ & ++ & - \\
\hline M & $8 \mathrm{M}$ & Undifferentiated & $\mathrm{N}$ & ++ & - & ++ \\
\hline $\mathrm{F}$ & $5 \mathrm{Ye}$ & Epithelial/mesenchymal & $\mathrm{N}$ & ++ & $+/-$ & - \\
\hline M & $11 \mathrm{M}$ & Fetal & $\mathrm{Y}$ & ++ & - & $+/-$ \\
\hline $\mathrm{F}$ & $9 \mathrm{M}$ & Fetal & $\mathrm{Y}$ & +++ & - & - \\
\hline M & $11 \mathrm{M}$ & Fetal & $\mathrm{Y}$ & +++ & - & +++ \\
\hline M & $4 \mathrm{Ye}$ & Fetal & Y & $+/-$ & - & +++ \\
\hline M & $6 \mathrm{M}$ & Fetal & Y & +++ & - & $+/-$ \\
\hline $\mathrm{F}$ & $2 \mathrm{Ye}$ & Fetal & Y & ++ & - & ++ \\
\hline $\mathrm{F}$ & $4 \mathrm{M}$ & Embryonal & Y & +++ & - & ++ \\
\hline M & $5 \mathrm{Ye}$ & Embryonal & $\mathrm{Y}$ & + & - & +++ \\
\hline $\mathrm{F}$ & $13 \mathrm{M}$ & Embryonal & Y & ++ & - & ++ \\
\hline M & $9 \mathrm{M}$ & Epithelial/mesenchymal & $\mathrm{Y}$ & +++ & - & $+/-$ \\
\hline M & $14 \mathrm{M}$ & Epithelial/mesenchymal & $\mathrm{Y}$ & +++ & - & ++ \\
\hline
\end{tabular}

F, female; M, male; Ye, years; M, months; N, no; Y, yes; T $\beta 4$, thymosin $\beta 4$; LNM, lymph node metastasis; EC, epithelial-cadherin; C $\beta$-c, cystolic $\beta$-catenin; -, negative; +/-, weak; + , mild; ++, moderate; +++, strong.

cytosolic accumulation of $\beta$-catenin were reduced in these samples (Fig. 2 and Table II). Overall, these results indicate that upregulation in the expression of $\mathrm{T} \beta 4$ may be associated with HB metastasis.
Expression of $T \beta 4$ promotes $H B$ cell motility. In order to investigate the association between endogenous T $\beta 4$ levels and the migratory capability of HB cells, siRNA was used to target T $\beta 4$ mRNA and knockdown T $\beta 4$ gene expression 


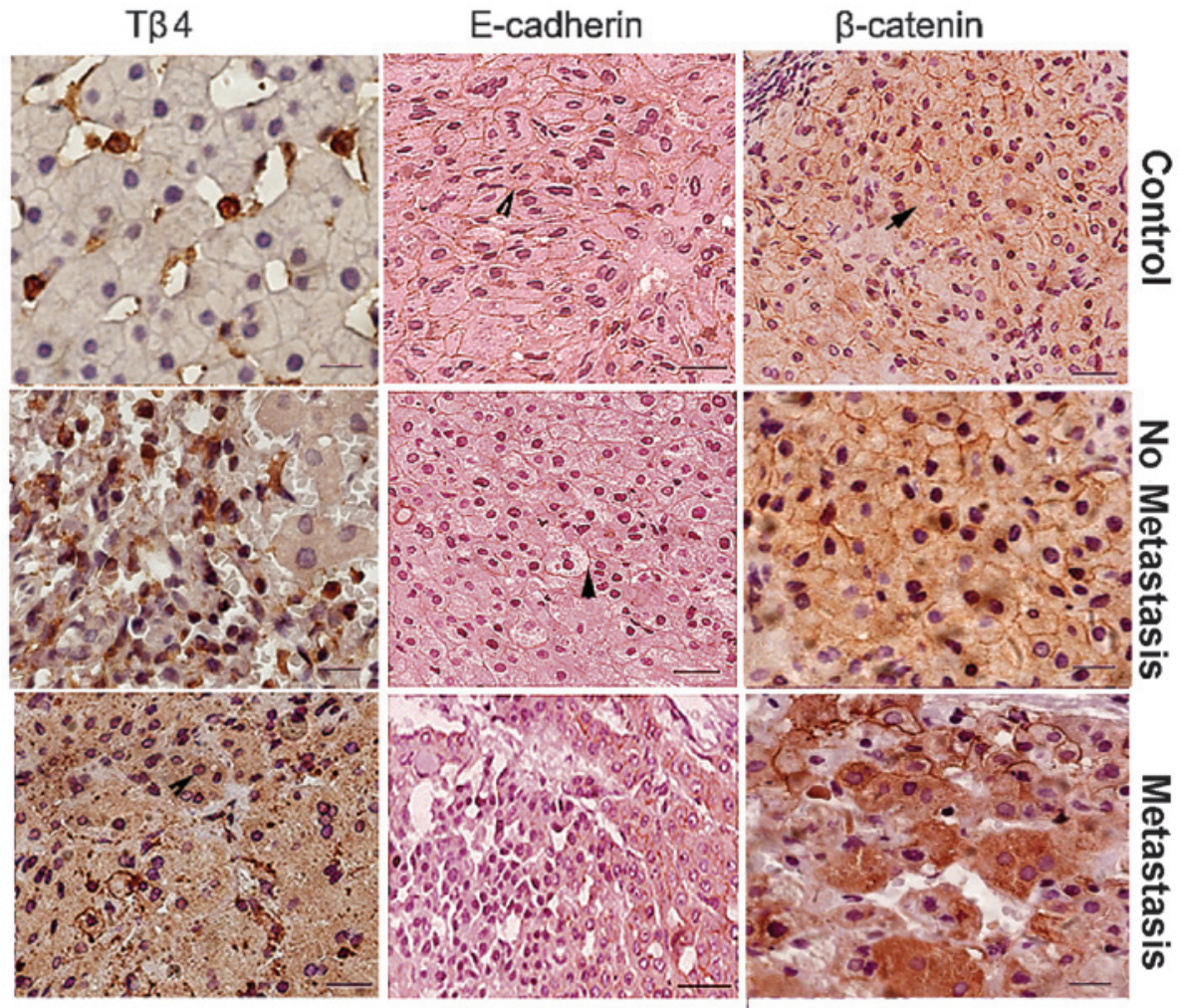

Figure 1. Expression of $\mathrm{T} \beta 4$ was associated with $\mathrm{HB}$ metastasis. The level of $\mathrm{T} \beta 4$ protein expression was higher in patients with HB metastasis compared with that in control and patients with $\mathrm{HB}$ without metastasis. $\mathrm{HB}$, hepatoblastoma; T $\beta 4$, thymosin $\beta 4$.

in HepG2 cells. Silencing of T $\beta 4$ expression in HepG2 cells (T $\beta 4$ siRNA-transfected cells; Fig. 2A and B) resulted in a significant reduction in cell migratory capability compared with that of control HepG2 cells, according to a wound healing assay $(\mathrm{P}<0.01$; Fig. $2 \mathrm{C}$ and $\mathrm{E})$. Following treatment with $\mathrm{T} \beta 4$ (siRNA + T 34 Fig. $2 \mathrm{C}$ and E) the migratory capability of HepG2 cells was significantly greater than that of control HepG2 cells, and significantly lower than that of T $\beta 4$ silenced (siRNA) HepG2 cells ( $\mathrm{P}<0.05$ and 0.01 , respectively). Similar results were observed in the Transwell assays $(\mathrm{P}<0.05 ;$ Fig. $2 \mathrm{D}$ and $\mathrm{F})$.

T $\beta 4$ depletion inhibits EMT in $H B$ cells. The results of the present study suggested that downregulated $\mathrm{T} \beta 4$ expression may be associated with reduced HepG2 cell migratory capability. Markers of EMT were examined in order to investigate the mechanisms underlying these observations. E-cadherin expression was higher in T $\beta 4$-siRNA-transfected HepG2 cells compared with that in control cells, whereas the expression levels of two mesenchymal markers $(\beta$-catenin and $\alpha$-SMA) were lower in T $\beta 4$-siRNA-transfected HepG2 cells compared with those in control cells (Fig. 3A and B). Since TGF- $\beta 1$ is involved in the induction of EMT (18), the association between T $\beta 4$ expression and TGF- $\beta 1$-induced EMT was examined. Following TGF- $\beta 1$ treatment, the expression of E-cadherin in HepG2 cells was significantly lower and the levels of $\mathrm{N}$-cadherin and $\alpha$-SMA were significantly higher, compared with those in the control HepG2 cells. Following transfection with T $\beta 4$-siRNA, the expression of genes involved in TGF- $\beta 1$-induced EMT was significantly reduced in HepG2 cells compared with that in control HepG2 cells (Fig. 3A and B).

\section{Discussion}

$\mathrm{T} \beta 4$ is a cellular, actin-sequestering protein, which is associated with angiogenesis induction and the metastatic potential of tumor cells (19-24). The results of the present study suggested that $\mathrm{T} \beta 4$ is involved in $\mathrm{HB}$ metastasis. $\mathrm{T} \beta 4$ expression was significantly higher in HB tissue cells compared with that in healthy adjacent cells (Fig. 1). Statistical analysis demonstrated that $\mathrm{T} \beta 4$ expression in tumor tissues was significantly associated with HB-derived lymph node metastasis (Table I and II). $\mathrm{T} \beta 4$ gene expression knockdown, using siRNA transfection, resulted in a decrease in the migratory capability of HepG2 cells compared with that in control cells (Fig. 2). Furthermore, the inhibition of T $\beta 4$ expression suppressed the process of TGF- 31 -induced EMT in HepG2 cells (Fig. 3).

Tumor metastasis is a multistep process, in which cancer cells disseminate from their primary sites and develop secondary malignant growths at distant sites. The process involves local invasion, intravasation, transportation, extravasation and colonization (25). EMT involves a series of steps, in which cell-cell and cell-extracellular matrix interactions are altered in order to release epithelial cells from the surrounding tissue (26). EMT has been shown to be involved in promoting metastasis in epithelium-derived carcinoma (25). A loss of E-cadherin has been hypothesized to promote $\beta$-catenin expression, which binds with the transcription factor, T-cell factor/lymphoid enhancer factor, and modulates gene transcription (27). In the present study, it was found that $T \beta 4$ was upregulated in HB metastatic liver samples; by contrast, E-cadherin expression and the cytosolic accumulation of $\beta$-catenin were downregulated in these specimens (Table I 

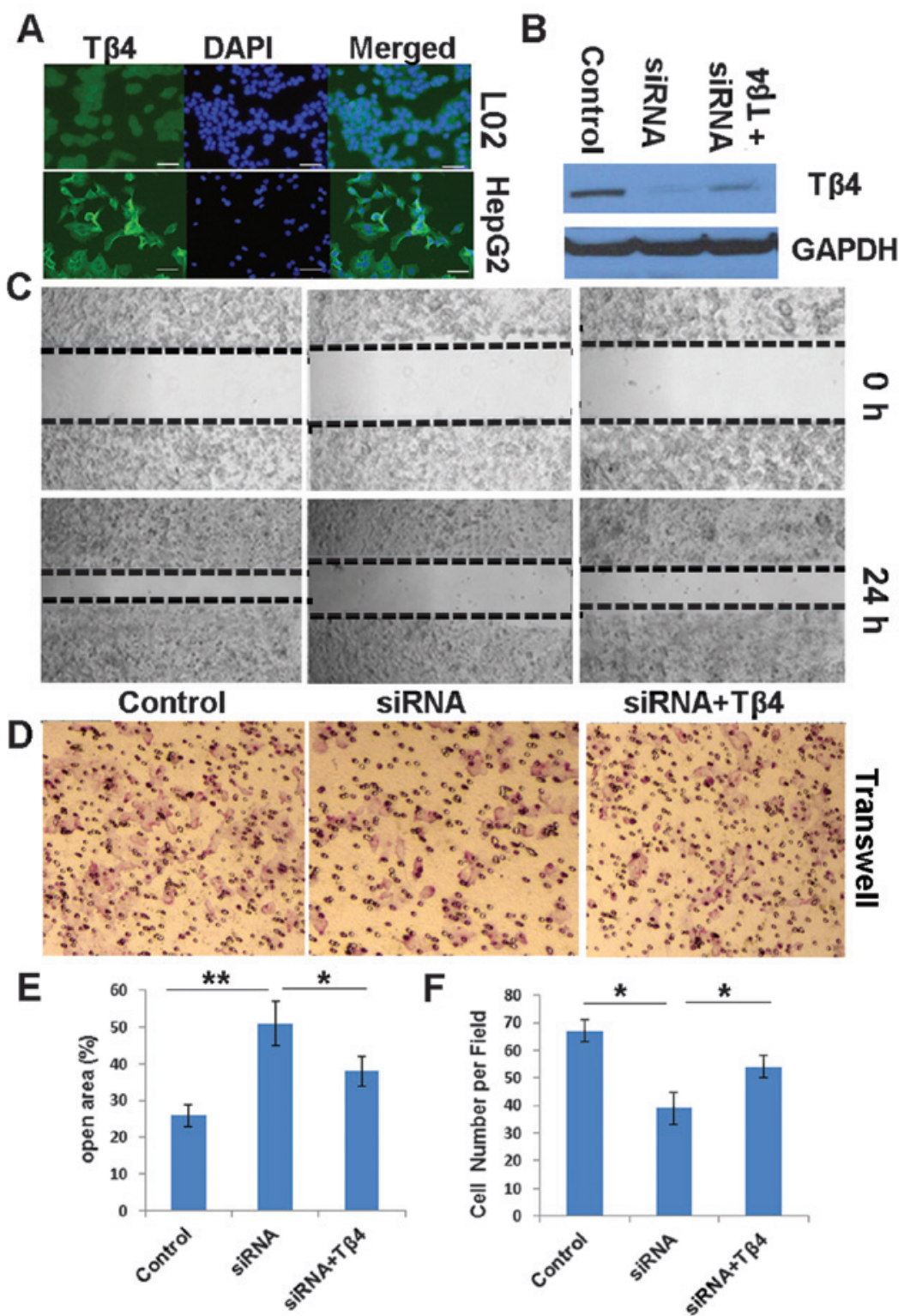

Figure 2. Knockdown of T $\beta 4$ gene expression inhibited the migratory capability of HepG2 cells compared with that of control cells. (A) Immunofluorescence analysis demonstrated that T $\beta 4$ protein was expressed strongly in HepG2 cells compared with that in L02 healthy cells following incubation for $48 \mathrm{~h}$. (B) T $\beta 4$ protein expression decreased following transfection with T 34 -siRNA. (C and E) Wound healing and (D and F) Transwell migration assays demonstrated that, following T $\beta 4$ gene expression knockdown, HepG2 cell migratory capability was significantly reduced compared with that in control cells. Magnification: $\mathrm{x} 40$. Data are presented as the mean \pm standard deviation. ${ }^{*} \mathrm{P}<0.05$ and ${ }^{* *} \mathrm{P}<0.01$. T $\beta 4$, thymosin $\beta 4$; siRNA, small interfering RNA; DAPI, 4',6-diamidino-2-phenylindole.

A

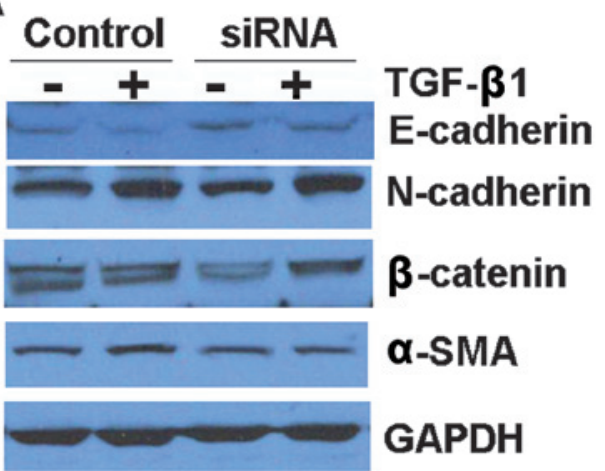

B

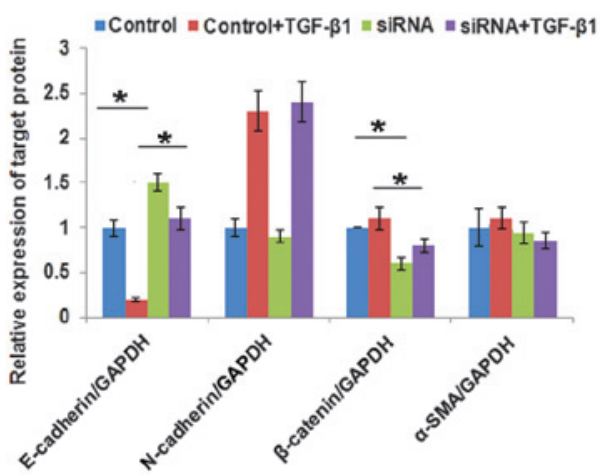

Figure 3. T $\beta 4$ knockdown suppresses the EMT process. (A and B) Downregulated T $\beta 4$ inhibited TGF- $\beta 1$-induced EMT in HepG2 cells. T $\beta 4$, thymosin $\beta 4$; siRNA, small interfering RNA; TGF- $\beta 1$, transforming growth factor $\beta 1$; E-cadherin, epithelial cadherin; N-cadherin, neural cadherin; GAPDH, glyceraldehyde 3-phosphate dehydrogenase; SMA, smooth muscle actin. 
I and Fig. 1). As the principle binding partner of $\beta$-catenin, E-cadherin is involved in the stabilization and promotion of $\beta$-catenin expression. E-cadherin and $\beta$-catenin are associated with the adhesion and the maintenance of epithelial cell layers. The upregulation of $\mathrm{T} \beta 4$ expression may lead to the downregulation of E-cadherin expression, and disrupt actin filaments (28). This may subsequently promote the release of $\beta$-catenin from the cell membrane, thereby activating target genes and facilitating HB metastasis. The TGF- $\beta$ pathway appears to induce EMT (29). In the present study, HepG2 cells were treated with TGF- $\beta 1$ in order to induce EMT. The expression E-cadherin was lower, and that of $\mathrm{N}$-cadherin and $\beta$-catenin was higher, in TGF- $\beta 1$-treated cells, compared with expression of these molecules in the control cells (Fig. 3). These results suggest that $\mathrm{T} \beta 4$ depletion may inhibit EMT in HB cells. Adherent cell locomotion is a highly integrated process, initiated by the forward extension of lamellipodia, followed by repeated cycles of protrusion, adhesion and contraction $(30,31)$. T $\beta 4$ is a candidate regulator of cell protrusion that is involved in protrusion-associated processes, such as actin polymerization and matrix metalloproteinase (MMP) expression. Wang et al (16) demonstrated that an increase in the invasiveness of SW480 colon carcinoma cells overexpressing T $\beta 4$, was associated with an increase in MMP-7 expression. The involvement of MMP expression in the processes underlying the association between $\mathrm{T} \beta 4$ expression and $\mathrm{HB}$ metastasis requires further investigation.

In conclusion, elevated $\mathrm{T} \beta 4$ expression in $\mathrm{HB}$ cells may promote $\mathrm{HB}$ metastasis via the deregulation of EMT.

\section{References}

1. Czauderna P, Lopez-Terrada D, Hiyama E, Häberle B, Malogolowkin MH and Meyers RL: Hepatoblastoma state of the art: pathology, genetics, risk stratification, and chemotherapy. Curr Opin Pediatr 26: 19-28, 2014.

2. Stocker JT: Hepatic tumors in children. Clin Liver Dis 5: 259-281, 2001.

3. Green LK and Silva EG: Hepatoblastoma in an adult with metastasis to the ovaries. Am J Clin Pathol 92: 110-115, 1989.

4. Gupta SK, Oommen S, Aubry MC, Williams BP and Vlahakis NE: Integrin $\alpha 9 \beta 1$ promotes malignant tumor growth and metastasis by potentiating epithelial-mesenchymal transition. Oncogene 32 : 141-150, 2013.

5. Yadav A, Kumar B, Datta J, Teknos TN and Kumar P: IL-6 promotes head and neck tumor metastasis by inducing epithelial-mesenchymal transition via the JAK-STAT3-SNAIL signaling pathway. Mol Cancer Res 9: 1658-1667, 2011.

6. Meng F, Han Y, Staloch D, Francis T, Stokes A and Francis H: The H4 histamine receptor agonist, clobenpropit, suppresses human cholangiocarcinoma progression by disruption of epithelial mesenchymal transition and tumor metastasis. Hepatology 54 $1718-1728,2011$

7. Zucchini-Pascal N, Peyre L and Rahmani R: Crosstalk between beta-catenin and snail in the induction of epithelial to mesenchymal transition in hepatocarcinoma: role of the ERK1/2 pathway. Int J Mol Sci 14: 20768-20792, 2013.

8. Cannito S, Novo E, Compagnone A, et al: Redox mechanisms switch on hypoxia-dependent epithelial-mesenchymal transition in cancer cells. Carcinogenesis 29: 2267-2278, 2008.
9. Nagamalleswari K and Safer D: Sequestered actin in chick embryo fibroblasts. Mol Cell Biochem 209: 63-67, 2000.

10. Reti R, Kwon E, Qiu P, Wheater M and Sosne G: Thymosin beta4 is cytoprotective in human gingival fibroblasts. Eur J Oral Sci 116: 424-430, 2008

11. Roy P, Rajfur Z, Jones D, Marriott G, Loew L and Jacobson K: Local photorelease of caged thymosin beta4 in locomoting keratocytes causes cell turning. J Cell Biol 153: 1035-1048, 2001.

12. Mu H, Ohashi R, Yang H et al: Thymosin beta10 inhibits cell migration and capillary-like tube formation of human coronary artery endothelial cells. Cell Motil Cytoskeleton 63: 222-230, 2006.

13. Francis Godschalk M: Pressure ulcers: a role for thymosin beta4. Ann N Y Acad Sci 1112: 413-417, 2007.

14. Smart N, Rossdeutsch A and Riley PR: Thymosin beta4 and angiogenesis: modes of action and therapeutic potential. Angiogenesis 10: 229-241, 2007.

15. Jo JO, Kang YJ, Ock MS, Kleinman HK, Chang HK, Cha HJ: Thymosin $\beta 4$ expression in human tissues and in tumors using tissue microarrays. Appl Immunohistochem Mol Morphol 19: 160-167, 2011.

16. Wang WS CP, Hsiao HL, Ju SY and Su Y: Overexpression of the thymosin beta- 4 gene is associated with malignant progression of SW480 colon cancer cells. Oncogene 22: 3297-3306, 2003.

17. Bataille F, Rohrmeier C, Bates R, et al: Evidence for a role of epithelial mesenchymal transition during pathogenesis of fistulae in Crohn's disease. Inflamm Bowel Dis 14: 1514-1527, 2008.

18. Flier SN, Tanjore H, Kokkotou EG, Sugimoto H, Zeisberg M and Kalluri R: Identification of epithelial to mesenchymal transition as a novel source of fibroblasts in intestinal fibrosis. J Biol Chem 285: 20202-20212, 2010.

19. Kim NS, Kang YJ, Jo JO, et al: Elevated expression of thymosin $\beta 4$, vascular endothelial growth factor (VEGF), and hypoxia inducible factor (HIF)- $1 \alpha$ in early-stage cervical cancers. Pathol Oncol Res 17: 493-502, 2011.

20. Liu JM, Kusinski M, Ilic V, et al: Overexpression of the angiogenic tetrapeptide AcSDKP in human malignant tumors. Anticancer Res 28: 2813-2817, 2008.

21. Cha HJ, Jeong MJ and Kleinman HK: Role of thymosin beta4 in tumor metastasis and angiogenesis. J Natl Cancer Inst 95: 1674-1680, 2003

22. Kim A, Son M, Kim KI, et al: Elevation of intracellular cyclic AMP inhibits NF-kappaB-mediated thymosin beta4 expression in melanoma cells. Exp Cell Res 315: 3325-3335, 2009.

23. Kielosto $M$, Nummela P, Järvinen K, Yin M and Hölttä E: Identification of integrins alpha6 and beta7 as c-Jun- and transformation-relevant genes in highly invasive fibrosarcoma cells. Int J Cancer 125: 1065-1073, 2009.

24. Kobayashi T, Okada F, Fujii N, et al: Thymosin-beta4 regulates motility and metastasis of malignant mouse fibrosarcoma cells. Am J Pathol 160: 869-882, 2002.

25. Tsai JH and Yang J: Epithelial-mesenchymal plasticity in carcinoma metastasis. Genes Dev 27: 2192-2206, 2013.

26. Radisky DC: Epithelial-mesenchymal transition. J Cell Sci 118: 4325-4326, 2005.

27. Semb H and Christofori G: The tumor-suppressor function of E-cadherin. Am J Hum Genet 63: 1588-1593, 1998.

28. Huang HC, Hu CH, Tang MC, Wang WS, Chen PM and Su Y: Thymosin beta4 triggers an epithelial-mesenchymal transition in colorectal carcinoma by upregulating integrin-linked kinase. Oncogene 26: 2781-2790, 2007.

29. Katsuno Y, Lamouille $S$ and Derynck R: TGF- $\beta$ signaling and epithelial-mesenchymal transition in cancer progression. Curr Opin Oncol 25: 76-84, 2013.

30. Lauffenburger DA and Horwitz AF: Cell migration: a physically integrated molecular process. Cell 84: 359-369, 1996.

31. Pollard TD and Borisy GG: Cellular motility driven by assembly and disassembly of actin filaments. Cell 112: 453-465, 2003. 